\section{(1)}

CrossMark

\title{
Chronic effects of air pollution on lung function after lung transplantation in the Systems prediction of Chronic Lung Allograft Dysfunction (SysCLAD) study
}

\author{
Meriem Benmerad ${ }^{1,2,3}$, Rémy Slama ${ }^{1,2,3}$, Karine Botturi ${ }^{4}$, Johanna Claustre ${ }^{5,6}$, \\ Antoine Roux ${ }^{7}$, Edouard Sage $^{7}$, Martine Reynaud-Gaubert $^{8}$, Carine Gomez $^{8}$, \\ Romain Kessler ${ }^{9}$, Olivier Brugière ${ }^{10}$, Jean-François Mornex ${ }^{11}$, Sacha Mussot ${ }^{12}$, \\ Marcel Dahan ${ }^{13}$, Véronique Boussaud ${ }^{14}$, Isabelle Danner-Boucher ${ }^{15}$, \\ Claire Dromer ${ }^{16}$, Christiane Knoop ${ }^{17}$, Annick Auffray ${ }^{18}$, Johanna Lepeule ${ }^{1,2,3}$ \\ Laure Malherbe ${ }^{19}$, Frederik Meleux ${ }^{19}$, Laurent Nicod ${ }^{20}$, Antoine Magnan ${ }^{4}$, \\ Christophe Pison ${ }^{5,6}$ and Valérie Siroux ${ }^{1,2,3}$ on behalf of the SysCLAD \\ consortium $^{21}$
}

@ERSpublications

Chronic exposure to air pollutants is associated with reduced lung function in lung transplant recipients http://ow.ly/gH8e304Qac4

Cite this article as: Benmerad M, Slama R, Botturi K, et al. Chronic effects of air pollution on lung function after lung transplantation in the Systems prediction of Chronic Lung Allograft Dysfunction (SysCLAD) study. Eur Respir J 2017; 49: 1600206 [https://doi.org/10.1183/13993003.00206-2016].

ABSTRACT An irreversible loss in lung function limits the long-term success in lung transplantation. We evaluated the role of chronic exposure to ambient air pollution on lung function levels in lung transplant recipients (LTRs).

The lung function of 520 LTRs from the Cohort in Lung Transplantation (COLT) study was measured every 6 months. The levels of air pollutants (nitrogen dioxide $\left(\mathrm{NO}_{2}\right)$, particulate matter with an aerodynamic cut-off diameter of $\mathrm{x} \mu \mathrm{m}(\mathrm{PMx})$ and ozone $\left.\left(\mathrm{O}_{3}\right)\right)$ at the patients' home address were averaged in the 12 months before each spirometry test. The effects of air pollutants on forced expiratory volume in $1 \mathrm{~s}(\mathrm{FEV} 1)$ and forced vital capacity (FVC) in \% predicted were estimated using mixed linear regressions. We assessed the effect modification of macrolide antibiotics in this relationship.

Increased 12-month levels of pollutants were associated with lower levels of FVC $\%$ pred $(-2.56 \%, 95 \%$ $\mathrm{CI}-3.86--1.25$ for $5 \mu \mathrm{g} \cdot \mathrm{m}^{-3}$ of $\mathrm{PM} 10 ;-0.75 \%, 95 \% \mathrm{CI}-1.38--0.12$ for $2 \mu \mathrm{g} \cdot \mathrm{m}^{-3}$ of $\mathrm{PM} 2.5$ and $-2.58 \%$, $95 \% \mathrm{CI}-4.63--0.53$ for $10 \mu \mathrm{g} \cdot \mathrm{m}^{-3}$ of $\mathrm{NO}_{2}$ ). In patients not taking macrolides, the deleterious association between PM and FVC tended to be stronger and PM10 was associated with lower FEV1.

Our study suggests a deleterious effect of chronic exposure to air pollutants on lung function levels in LTRs, which might be modified with macrolides.

This article has supplementary material available from erj.ersjournals.com

Received: Jan 272016 | Accepted after revision: Sept 202016

Support statement: We are indebted to Programme Hospitalier de Recherche Clinique 2008 (Paris, France), Vaincre La Mucoviscidose (Paris, France) and Association Gregory Lemarchal for launching the project within the 11 French lung transplantation centres within the Cohort Of Lung Transplantation (COLT; Programme Transplantation 2008, PRTP-13, ClinicalTrials.gov Identifier: NCT00980967); Swiss National research fund supporting the STCS and, in particular, the lung transplant section (number 3347CO-108795). The SysCLAD study is an EU-funded project, HEALTH-F5-2012, grant agreement No. 305457 under the Seventh Framework Program (FP7). Funding information for this article has been deposited with the Open Funder Registry.

Conflict of interest: Disclosures can be found alongside this article at erj.ersjournals.com

Copyright OERS 2017 
Affiliations: 'Université Grenoble Alpes, CNRS UMR 5309, IAB, Team of Environmental Epidemiology applied to Reproduction and Respiratory Health, Grenoble, France. ${ }^{2}$ INSERM U1209, IAB, Team of Environmental Epidemiology applied to Reproduction and Respiratory Health, Grenoble, France. ${ }^{3} \mathrm{CHU}$ de Grenoble, IAB, Team of Environmental Epidemiology applied to Reproduction and Respiratory Health, Grenoble, France. ${ }^{4}$ Institut du Thorax - INSERM UMR 1087/CNRS UMR 6291, CHU de Nantes, Nantes, France. ${ }^{5}$ Université Grenoble Alpes, Grenoble, France. ${ }^{6}$ Clinique Universitaire de Pneumologie, Pôle Thorax et Vaisseaux, CHU de Grenoble, INSERM U1055, Grenoble, France. ${ }^{7}$ Thoracic Surgery Dept, Foch Hospital, Université Versailles Saint-Quentin-en-Yvelines, UPRES EA220, Suresnes, France. ${ }^{8}$ Service de Pneumologie et transplantation pulmonaire, Centre de Compétences des Maladies rares Pulmonaires et de l'Hypertension Pulmonaire, $\mathrm{CHU}$ Nord de Marseille, Aix Marseille Université, Marseille, France. ${ }^{9}$ Pôle Pathologie thoracique, CHU de Strasbourg, Strasbourg, France. ${ }^{10}$ Unité Pneumologie, Hôpital Bichat, Claude-Bernard AP-HP, Paris, France. ${ }^{11}$ Université de Lyon, Université Lyon 1, UMR754 INRA, Hospices civils de Lyon, Lyon, France. ${ }^{12}$ Service de Chirurgie Thoracique, Vasculaire et Transplantation Cardiopulmonaire Centre Chirurgical Marie Lannelongue, Le Plessis Robinson, France. ${ }^{13}$ Chirurgie thoracique, Hôpital Larrey, CHU de Toulouse, Toulouse, France. ${ }^{14}$ Chirurgie cardiovasculaire, Hôpital Européen Georges-Pompidou H.E.G.P. AP-HP, Paris, France. ${ }^{15}$ Service de pneumologie, CHU de Nantes, Nantes, France. ${ }^{16}$ Unité d'insuffisance respiratoire et transplantation, $\mathrm{CHU}$ de Bordeaux, Bordeaux, France. ${ }^{17}$ Service de pneumologie, Hôpital Erasme, Brussels, Belgium. ${ }^{18}$ Météo France, Lyon, France. ${ }^{19}$ Direction des Risques Chroniques, INERIS, Verneuil-en-Halatte, France. ${ }^{20}$ Service de Pneumologie, CHU Vaudois, Lausanne, Switzerland. ${ }^{21} \mathrm{~A}$ list of members of the SysCLAD consortium can be found in the Acknowledgements section.

Correspondence: Valérie Siroux, Institute for Advanced Biosciences, Université Grenoble Alpes, INSERM U1209, CNRS UMR 5309, Team of Environmental Epidemiology Applied to Reproduction and Respiratory Health, BP170, F-38042 Grenoble Cedex 9, France. E-mail: valerie.siroux@univ-grenoble-alpes.fr

\section{Introduction}

Lung transplantation is a relevant option to preserve quality of life and survival in selected patients suffering from end-stage respiration diseases. However, lung transplantation is still hampered by a high incidence of chronic lung allograft dysfunction (CLAD), characterised by an irreversible loss in lung function. CLAD, a term recently introduced, is difficult to define because of the lack of agreement in its definition and its determinants are poorly understood [1,2]. Attention has so far been given to clinical predictors, while the role of environmental factors has little been considered until recently [3]. In population-based studies, chronic exposure to air pollution has been associated with an increased incidence and prevalence of chronic respiratory diseases (asthma, chronic obstructive pulmonary disease) and lung function impairment [4-8]. Chronic exposure to air pollutants has been associated with lower forced expiratory volume in $1 \mathrm{~s}(\mathrm{FEV} 1)$ and forced vital capacity (FVC) and a faster lung function decline in adults [7,9] as well as with deficits in lung-function growth in children [10, 11]. Also, long-term improvements in air quality have been associated with significant improvement in lung function development in children [12] and with attenuated age-related decline in lung function in adults [13].

Few studies have estimated the impact of chronic exposure to ambient air pollutants in lung transplant recipients (LTRs), a population with a potential higher sensitivity to air pollution exposure due to cumulative effects of ischaemic reperfusion insult and innate and adaptive immune activation. Two previous studies have indicated that traffic-related air pollution, assessed with proximity to major road, was associated with the risk of development of CLAD, bronchiolitis obliterans syndromes (BOS) and of mortality after lung transplantation $[14,15]$. The Canadian study did not detect any significant association between CLAD occurrence and mean annual concentrations of particulate matter with an aerodynamic cut-off of $2.5 \mu \mathrm{m}(\mathrm{PM} 2.5)$, ozone $\left(\mathrm{O}_{3}\right)$ and nitrogen dioxide $\left(\mathrm{NO}_{2}\right)$ estimated at the residential address using nearby fixed-site monitoring stations [14]. Recent results (presented in an abstract) from a study based on 13 European centres indicated that the incidence of CLAD and mortality were significantly associated with particulate matter with an aerodynamic cut-off of $10 \mu \mathrm{m}$ (PM10) exposure estimated at the residential address, only in patients not taking macrolide antibiotics [16]. None of these studies directly addressed the effect of exposure to air pollutants on lung function level, considered as a continuous parameter.

We aimed to study the impact of chronic exposure to ambient air pollution on the levels of lung function following lung transplantation.

\section{Methods \\ Population}

The Cohort in Lung Transplantation (COLT) study (http://clinicaltrials.gov; identifier: NCT00980967) recruited 827 lung transplant recipients (LTRs) between September 2009 and August 2013 in France. COLT is part of the Systems prediction of Chronic Lung Allograft Dysfunction (SysCLAD) study, a project funded by the European Commission (FP-7) aimed at identifying novel predictive biomarkers of CLAD [17]. For the present analysis, we selected 520 COLT participants who were transplanted before July 2013 
while residing in France, had at least one lung function measurement 6 months or more after transplantation and had the residential address geolocalised (figure 1).

\section{Outcome measurements}

Spirometry was performed at 1 and 6 months post-transplantation and then every 6 months. Our analysis focused on FEV1 and FVC expressed as \% predicted value estimated with age, height and sex from the Global Lung Initiative equations [18].

\section{Air pollution exposure (online supplementary material, figures E1, E2, E3 and table E1)}

Chronic exposures to $\mathrm{PM} 2.5$ and $\mathrm{PM}_{10}, \mathrm{NO}_{2}$, and ozone $\mathrm{O}_{3}$ were assessed using nation-wide air pollution models developed by INERIS (Institut National de l'Environnement industriel et des Risques), the French national institute for industrial environment and risks. These are the finest spatial $\left(1 \times 1 \mathrm{~km}\right.$ grid for $\mathrm{NO}_{2}$ and PM and $4 \times 4 \mathrm{~km}$ for ozone) and temporal (daily data) resolution models currently available for the whole French territory. A 5-year modelling period (2009-2013) was considered. Through a geostatistical (Kriging) analysis, the exposure models combined data from the CHIMERE chemistry-transport model, a validated model in Europe $[19,20]$ with measurements from the permanent network of air quality monitoring stations. The precision of Kriging was evaluated on a daily basis through leave-one-out and k-fold cross-validation, and usual annual skill scores (bias, mean absolute normalised error, root mean square error and correlation) were computed.

The residential address of each participant was geocoded using the French cadastral map, a building matching technique [21]. The 12-month average levels of air pollutants at the participant's residential address before each lung function test was first considered and secondary analyses were conducted considering shorter exposure windows (6-month, 3-month and 1-month). Figure 2 shows the 12-month average concentration of pollutants in France in 2011.

We considered each FEV1 and FVC measurement performed at least 6 months post-transplant until December 31, 2013.

\section{Statistical analysis}

We performed longitudinal analyses of the relation between the 12-month average levels of each air pollutant and repeated FEV1 \% pred and FVC \% pred levels using mixed linear regression model. The models estimate the risks for $\mathrm{FEV}_{1} \%$ pred and FVC \% pred levels repeatedly measured over time, and do not study FEV1 or FVC decline. Using a thorough search of the literature, we identified as potential confounders variables that were theoretically related to lung function or to the development of CLAD in lung transplant patients. For each pollutant, outcome and exposure window considered, we applied three models: an unadjusted model (M0), a model adjusted on LTR characteristics (age, sex, smoking status, body mass index), donor characteristics (age, smoking status), lung transplantation characteristics (type of lung transplantation,

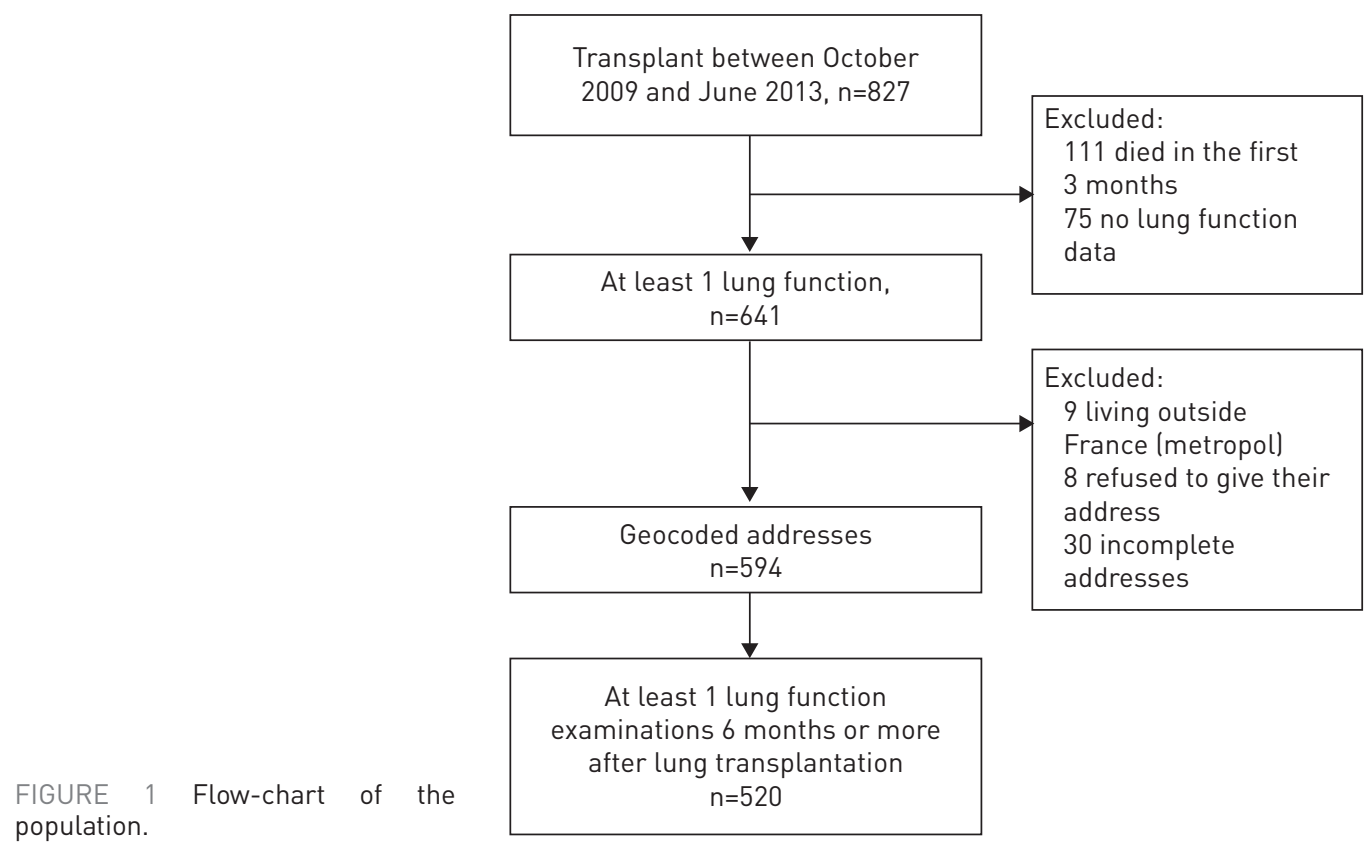




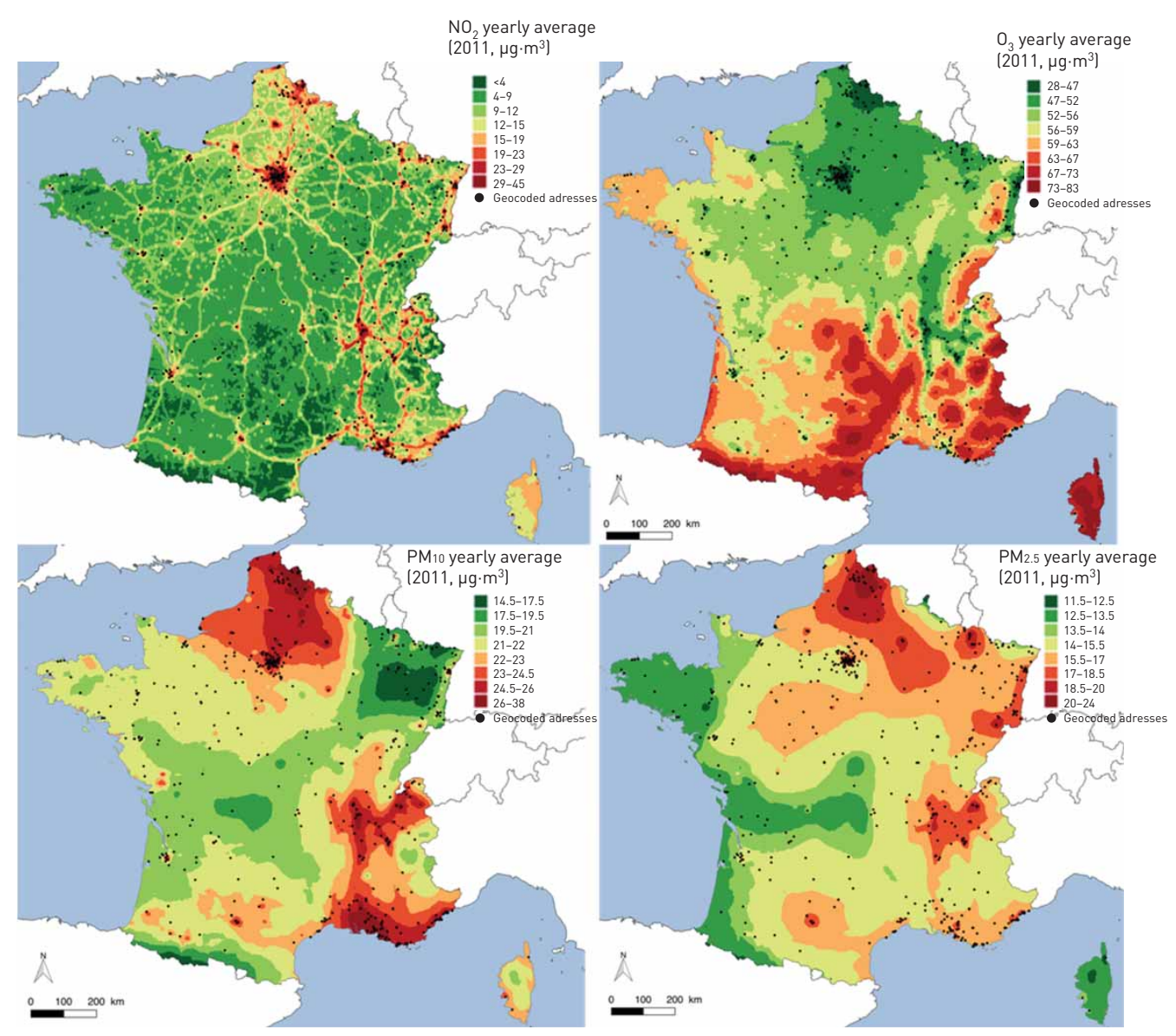

FIGURE 2 Averaged 12-month concentration of particulate matter with an aerodynamic cut-off of $2.5 \mu \mathrm{m}$ (PM2.5) and $10 \mu \mathrm{m}$ (PM10), $\mathrm{NO}_{2}$ and $\mathrm{O}_{3}$ across France in 2011.

indication, sex mismatch, anti-human leukocyte antigen (HLA) antibodies, transplant centre and living area (rural, city centre, suburbs, small city) (M1); a model further adjusted on post-transplant events (treated Pseudomonas spp. infection, cytomegalovirus (CMV) treated disease, immunosuppression induction and acute rejection treated episodes), which could be intermediate factors in the causal chain between air pollutants exposure and lung function (M2) (online supplementary figure E4). As sensitivity analysis, we fitted a parsimonious model adjusted for potential confounders that were related to FEV1 \% pred or FVC \% pred and to at least one air pollutant at the level of $\mathrm{p}<0.20$. When considering the 6-month, 3-month and 1-month average levels of air pollutants, models $\mathrm{M}_{0}, \mathrm{M}_{1}$ and $\mathrm{M}_{2}$ were further adjusted on temperature and humidity averaged during the same exposure window (estimated from the nearest Météo France station). Bi-pollutant models were further run to address the independent effects of pollutants.

Air pollutant exposures were considered as continuous variables (main analyses) or coded in tertiles (secondary analyses). Intraclass correlation coefficients (ICC) were estimated for each exposure window to quantify the within-subject variability of the air pollutant exposure over time. We stratified the analysis on the use of macrolides to attempt to replicate the findings from a previous study indicating that macrolides might prevent the deleterious effects of air pollution on LTRs [16]. We further assessed the association considering the 6-month average levels of air pollutants after each lung function test. Under our working hypothesis, no or decreased association as compared to those observed for the 6-month before each lung function tests would be expected. Because a large study area entails larger exposure contrasts, but also increases the potential for confounding [22], we further stratified the analysis on living area (rural versus urban). Data management and statistical analyses were conducted with SAS version 9.4 (SAS Institute Inc., Cary, NC, USA) software package and R software environment (R Project for Statistical Computing; www.r-project.org).

\section{Results}

Population description

The population included 520 lung transplantation, 54\% men; the mean age was 43 years (range 1368 years) (table 1). The mean duration of follow-up was 23 months (range 6-48 months). Over half (51\%) 
TABLE 1 Description of study population

Lung transplant patient characteristics

Male sex

282 (54.2)

Age years

$43.1 \pm 15.2$

BMI $\mathrm{kg} \cdot \mathrm{m}^{-2}$

$20.9 \pm 4.2$

Smoking status

Non-smoker

$263(51.3)$

Ex-smoker

$236(46)$

Current smoker

$14(2.7)$

Indications

Emphysema/COPD

173 (33.3)

Cystic fibrosis

$211(40.6)$

Pulmonary fibrosis

$71(13.7)$

Pulmonary arterial hypertension

43 (8.3)

Other

$22(4.2)$

Procedures: double

422 (81.2)

Centre

Foch

$133(25.6)$

Marseille

103 (19.8)

Strasbourg

$75(14.4)$

Other

209 (40.2)

Living area

Rural

93 (17.9)

City centre

Suburbs

167 (32.1)

Small city

$206(39.6)$

$54(10.4)$

Donor characteristics

$43.0 \pm 15.4$

Age years

193 (38.2)

Smoker

174 (33.5)

Sex mismatch

HLA mismatch

$3(0.6)$

$24(4.6)$

$72(13.8)$

89 (17.1)

45 (8.7)

Unknown

$287(55.2)$

$158(30.4)$

Anti-HLA antibodies

$339.5 \pm 96$

\section{Post-transplant events}

CMV treated disease

$138(27.1)$

Other infection

187 (36.7)

Acute rejection treated episodes

$346(67.4)$

treated Pseudomonas spp. infection

241 (47)

Induction therapy

No

160 (31.3)

205 (40)

Thymoglobulines-polyclonal

147 (28.7)

Thymoglobulines- monoclonal

259 (51.3)

\section{ung function at the best value}

Best FEV 1 L

$2.7 \pm 0.8$

Best FEV1 \% predicted

$79.2 \pm 19.0$

$3.4 \pm 0.9$

Best FVC \% predicted

$81.1 \pm 16.5$

Air pollutant concentrations $\mu \mathrm{g} \cdot \mathrm{m}^{-3}$

PM2.5

12-month

$15.0(13.8-16.6)$

6-month

$14.4(12.0-17.2)$

3-month

$13.5(10.9-17.4)$

1-month

$12.8(10.1-17.9)$ 
TABLE 1 Continued

Variables

All $(n=520)$

$\mathrm{PM} 10$

12-month

$21.7(19.8-24.2)$

6-month

$21.5(18.5-24.5)$

3-month

$20.6(17.5-24.7)$

1-month

$20.0(16.7-25.1)$

$\mathrm{NO}_{2}$

12-month

$17.3(12.4-22.8)$

6-month

$16.3(11.6-22.4)$

3-month

$16.0(10.8-22.3)$

1-month

$15.7(10.6-22.9)$

$\mathrm{O}_{3}$

12-month

$52.5(46.9-57.3)$

6-month

$53.3(44.7-61.6)$

3-month

53.4 (41.9-63.8)

1-month

$51.6(39.0-64.5)$

Data are presented as $\mathrm{n}(\%)$, mean \pm SD or median (interquartile range). BMI: body mass index; COPD: chronic obstructive pulmonary disease; HLA: human leukocyte antigen; CMV: cytomegalovirus; FEV1: forced expiratory volume in $1 \mathrm{~s}$; FVC: forced vital capacity; PMx: particulate matter with an aerodynamic cut-off diameter of $\mathrm{x} \mu \mathrm{m}$.

of the LTRs had never smoked and 3\% were current smokers. Most of the subjects had double lung transplantation (81\%). The main underlying diseases were cystic fibrosis (41\%), emphysema/chronic obstructive pulmonary disease (33\%) and pulmonary fibrosis (14\%). Mean donor age was 43 years, 38\% of donors had ever smoked and one-third did not have the same sex as recipients. Regarding post-transplant events, $27 \%$ of the LTRs had at least one CMV treated disease, $37 \%$ had other infections, $47 \%$ treated Pseudomonas spp. infection and $67 \%$ had at least one acute rejection treated episode. Half of the LTRs took macrolide antibiotics during the follow-up period.

The median (interquartile range) of the 12-month $\mathrm{PM} 2.5, \mathrm{PM}_{10}, \mathrm{NO}_{2}$ and $\mathrm{O}_{3}$ levels were 15.0 (13.8-16.6), 21.7 (19.8-24.2), 17.3 (12.4-22.8) and $52.5(46.9-57.3) \mu \mathrm{g} \cdot \mathrm{m}^{-3}$, respectively, and were higher in the urban area (city centre and suburbs) compared with the rural/small cities area, except for ozone (online supplementary figure E5). Considering shorter exposure window decreased the within-subject correlation of the air pollutant levels assessed over-time (ICC for the 12-month average exposure varied between 0.89 for PM2.5 to 0.99 for $\mathrm{NO}_{2}$, and $\mathrm{O}_{3}$ and decreased to 0.47 for $\mathrm{PM} 2.5$ and 0.83 for $\mathrm{NO}_{2}$ when considering the 1-month exposure window, online supplementary table E2). Using the 12-month average exposures, exposure to $\mathrm{NO}_{2}$ was positively correlated with exposure to PM2.5 and PM10 (Pearson's r values were 0.6 and 0.7 respectively) and negatively correlated with $\mathrm{O}_{3}$ (Pearson $\mathrm{r}-0.7$ ), $\mathrm{p}<0.0001$ for all (online supplementary table E3).

Association between air pollution exposure and lung function levels in the whole population Among all lung function measurements (1833 measurements among 520 subjects), mean (interquartile range) $\mathrm{FEV}_{1} \%$ pred and FVC \% pred were 69.5\% (54-85\%) and 76\% (64-89\%), respectively. The 12-month PM10, PM2.5 and $\mathrm{NO}_{2}$ levels were associated with lower FVC \% pred levels (table 2 and figure 3); a $5 \mu \mathrm{g} \cdot \mathrm{m}^{-3}$ increase in PM10 a $2 \mu \mathrm{g} \cdot \mathrm{m}^{-3}$ increase in $\mathrm{PM} 2.5$ and a $10 \mu \mathrm{g} \cdot \mathrm{m}^{-3}$ increase in $\mathrm{NO}_{2}$ level were associated with lower levels of FVC \% pred $(-2.56 \%, 95 \%$ CI $-3.86--1.25$ for PM10; $-0.75 \%, 95 \%$ CI $-1.38--0.12$ for PM2.5; and $-2.58 \%, 95 \% \mathrm{CI}-4.63--0.53$ for $\mathrm{NO}_{2}$ ). PM10 and $\mathrm{NO}_{2} 12$-month levels were not associated with FEV1 \% pred while PM2.5 was associated with higher FEV1 \% pred $(\mathrm{p}=0.03)$. Higher exposure to $\mathrm{O}_{3}$ was significantly associated with higher FEV1 \% pred and FVC \% pred levels (table 2). When coding air pollutants in tertiles, similar results were observed for FVC \% pred, and the previous trend for a positive association between $\mathrm{PM}_{2.5}$ and FEV1 \% pred totally disappeared (table 3 ).

\section{Analyses stratified on the use of macrolide antibiotics}

Patients who took macrolides differed from those who did not take macrolides regarding some post-lung transplantation events (more infections, more acute rejection treated episodes, less induced therapy), lung function level (lower $\mathrm{FEV}_{1} \%$ pred and $\mathrm{FVC} \%$ pred values), and air pollution exposures (higher 12-month exposure to $\mathrm{PM} 2.5$ and $\mathrm{NO}_{2}$ ) (online supplementary table $\mathrm{E} 4$ ).

Analyses stratified on the use of macrolides showed stronger association between PM2.5 and FVC \% pred in LTRs without macrolides than with macrolides (test for interaction, $\mathrm{p}=0.12$ ) and a similar trend was observed for PM10 (test for interaction, $\mathrm{p}=0.47$ ) (figure 3, online supplementary table E5). For FEV1 \% 
TABLE 2 Association of air pollutants exposure with levels of FEV1 \% predicted and FVC \% predicted

\begin{tabular}{|c|c|c|c|c|c|c|c|c|}
\hline \multirow{2}{*}{$\begin{array}{l}\text { Outcome by window } \\
\text { of exposure and model }\end{array}$} & \multicolumn{2}{|c|}{ PM2.5 (for $2 \mu \mathrm{g} \cdot \mathrm{m}^{-3}$ ) } & \multicolumn{2}{|c|}{$\mathrm{PM}_{10}$ (for $5 \mu \mathrm{g} \cdot \mathrm{m}^{-3}$ ) } & \multicolumn{2}{|c|}{$\mathrm{NO}_{2}$ ( for $10 \mu \mathrm{g} \cdot \mathrm{m}^{-3}$ ) } & \multicolumn{2}{|c|}{$0_{3}\left(\right.$ for $10 \mu g \cdot \mathrm{m}^{-3}$ ) } \\
\hline & Beta \pm SE & p-value & Beta \pm SE & p-value & Beta \pm SE & p-value & Beta \pm SE & p-value \\
\hline \multicolumn{9}{|l|}{ 12-month } \\
\hline MO & $0.85 \pm 0.38$ & 0.02 & $-0.13 \pm 0.76$ & 0.86 & $-1.73 \pm 1.09$ & 0.11 & $1.86 \pm 1.01$ & 0.06 \\
\hline M1 & $0.82 \pm 0.38$ & 0.03 & $0.64 \pm 0.78$ & 0.41 & $-0.86 \pm 1.2$ & 0.47 & $3.5 \pm 1.16$ & 0.003 \\
\hline MO & $0.14 \pm 0.24$ & 0.56 & $-0.11 \pm 0.51$ & 0.82 & $-2.36 \pm 0.88$ & 0.01 & $0.91 \pm 0.42$ & 0.03 \\
\hline M1 & $0.13 \pm 0.25$ & 0.60 & $0.09 \pm 0.52$ & 0.86 & $-1.62 \pm 0.95$ & 0.09 & $0.72 \pm 0.43$ & 0.10 \\
\hline M2 & $0.15 \pm 0.25$ & 0.54 & $0.08 \pm 0.52$ & 0.87 & $-1.84 \pm 0.95$ & 0.05 & $0.78 \pm 0.43$ & 0.07 \\
\hline \multicolumn{9}{|l|}{ FVC } \\
\hline \multicolumn{9}{|l|}{ 12-month } \\
\hline MO & $-0.78 \pm 0.32$ & 0.01 & $-3.01 \pm 0.63$ & $<0.0001$ & $-3.26 \pm 0.93$ & 0.0005 & $1.01 \pm 0.86$ & 0.24 \\
\hline M1 & $-0.63 \pm 0.21$ & 0.002 & $-1.52 \pm 0.44$ & 0.0005 & $-2.63 \pm 0.82$ & 0.001 & $0.85 \pm 0.36$ & 0.02 \\
\hline M2 & $-0.61 \pm 0.21$ & 0.003 & $-1.52 \pm 0.44$ & 0.0005 & $-2.75 \pm 0.82$ & 0.001 & $0.88 \pm 0.36$ & 0.02 \\
\hline
\end{tabular}

PMx: particulate matter with an aerodynamic cross section of $x \mu \mathrm{m}$; FEV1: forced expiratory volume in $1 \mathrm{~s}$; FVC: forced vital capacity; M0: crude model estimated on 520 patients (1833 measurements); M1: model adjusted on recipient age (continuous), sex, smoking status of both donor and recipient, body mass index (continuous), donor age, type of lung transplant, underlying disease, sex mismatch, anti-human leukocyte antigen antibodies, transplant centre, living area and, for the 6-month, 3-month and 1-month exposure, on temperature and humidity, estimated on 495 patients (1770 measurements); M2: M1 model further adjusted on treated Pseudomonas infection, cytomegalovirus treated disease, immunosuppression induction and acute rejection treated episodes, estimated on 487 patients (1751 measurements).

pred, higher exposure to PM2.5 and PM10 was associated with lower FEV1 \% pred in LTRs not taking macrolides, while an inverse association was observed in LTRs taking macrolide (tests for interaction, $\mathrm{p}=0.001$ and 0.01 , respectively). Similar patterns of association were observed when considering the macrolide treatment only in the first 6 months following lung transplantation ( 68 patients took macrolides in the first 6 months) (online supplementary figure E6).

\section{Sensitivity analyses}

The analysis conducted on the actual FEV1 and FVC values and further adjusted on height led to the same conclusion (online supplementary table E6). The parsimonious model showed very similar results compared with model M2 (online supplementary figure E7). When stratifying on the type of area, the association between the 12-month average exposure levels to PM2.5, PM10 and $\mathrm{NO}_{2}$ and lower FVC levels were observed in urban but not in rural areas, where exposure contrasts were lower. Higher exposure to $\mathrm{O}_{3}$ was associated with higher level of FEV1 in urban area, and no association was found in rural areas (online supplementary table E7). When considering shorter exposure windows (6-month and 3-month), results for FVC \% pred were similar as those for the 12-month and a higher $\mathrm{NO}_{2}$ exposure was significantly associated with lower FEV1 (table 2, online supplementary table E8). Considering PM and $\mathrm{NO}_{2}$ exposures, the 6 months following the lung function test decreased the magnitude of the association with FVC (compared with the analysis using the 6-month before the lung function test), as expected under the assumption of a causal effect of exposures (online supplementary table E9). Similarly, the level of association between $\mathrm{NO}_{2}$ and FEV1 decreased.

The 12-month PM10 levels remained significantly associated with lower FVC \% pred in models further adjusted on $\mathrm{PM} 2.5, \mathrm{NO}_{2}$ or $\mathrm{O}_{3}$, and the magnitude of the association remained similar, while the estimated effect of $\mathrm{NO}_{2}$ decreased in the bi-pollutant model. The 12-month $\mathrm{NO}_{2}$ levels remained significantly associated with FEV1 \% pred in the model further adjusted on PM2.5 or PM10 but not when adjusting on $\mathrm{O}_{3}$ (table 4).

\section{Discussion}

This longitudinal study is the first to address the possible effect of chronic exposure to air pollution on lung function levels in LTRs. Higher PM2.5, PM10 and $\mathrm{NO}_{2}$ levels were associated with lower FVC levels; the association with PM10 remained in bi-pollutant models and the association with PM2.5 tended to be stronger in LTRs not taking macrolides. 

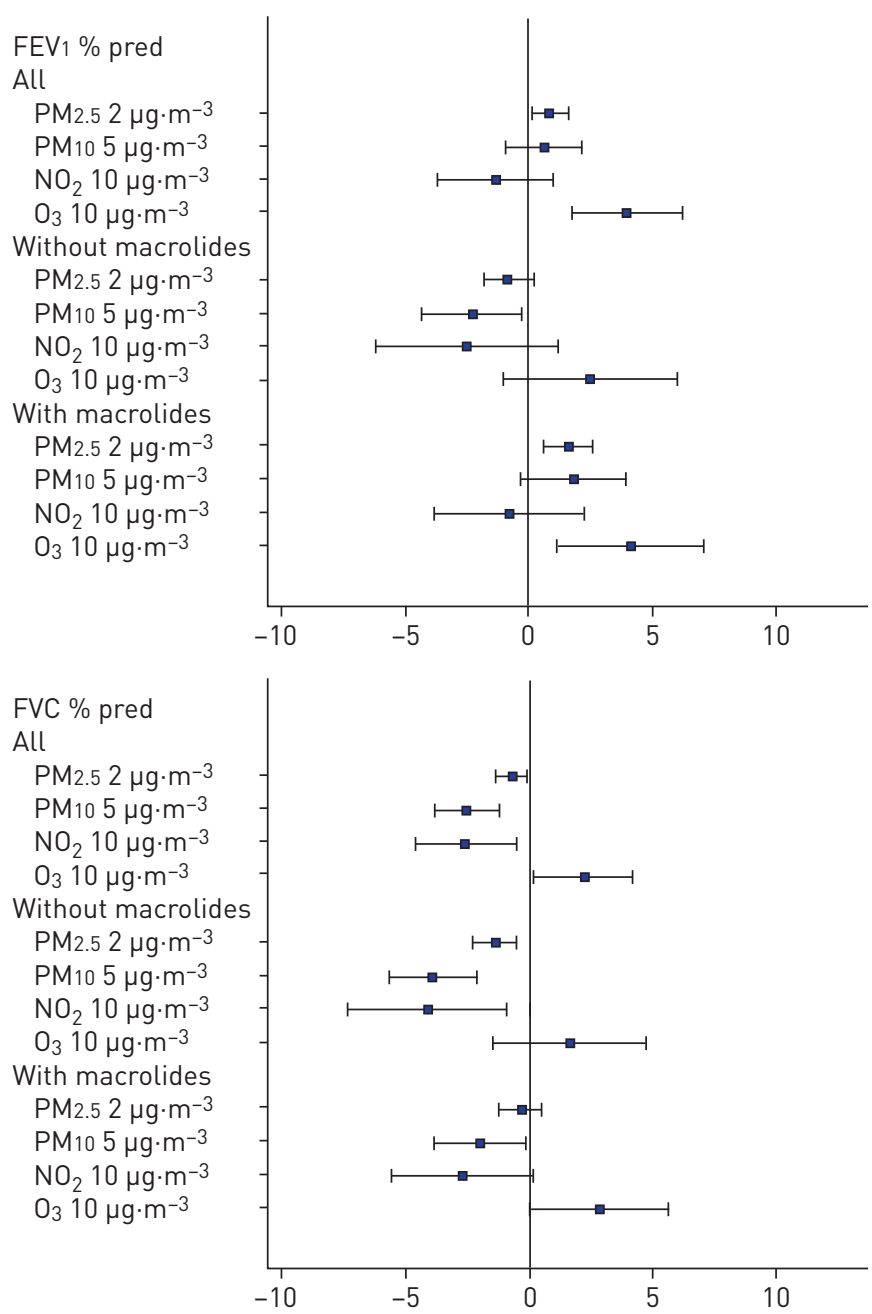

FIGURE 3 Adjusted associations between air pollutants exposure and level of (a) FEV1 \% predicted and (b) FVC $\%$ predicted in the whole population and according to the use of macrolides. PMx: particulate matter with an aerodynamic cross section of $\mathrm{x} \mu \mathrm{m}$.

A major strength of the study relates to the study population, a cohort of 520 very well characterised lung-transplant patients across France, with in total 1833 spirometric measurements, and the prospective longitudinal and multicentre design compared with international registries unable to yield such specific information [23]. The analysis of lung function parameters as continuous measurements allows a more objective assessment of the respiratory health outcome in lung transplant patients compared with the use of CLAD which suffers from a lack of an agreed definition. One of the limitations of the study relates to the length of follow-up: too short to accurately address the lung function trajectory. Consequently, our results cannot be extrapolated to CLAD or BOS phenotypes. We were able to adjust for a large number of potential confounders, including recipient and donor individual characteristics including smoking status, lung-transplant characteristics and post-lung transplant events, and most results were robust to such adjustments. We considered four pollutants and two outcomes, leading to an increased probability of chance findings. Noteworthy, the deleterious effect of PM10 on FVC remained significant using the stringent Bonferroni correction (0.0062).

A further strength lies in the assessment of air pollutant exposure at the patient's home, using the most accurate geocoding technics [21] and the exposure model with the finest spatial and temporal resolution available to cover the whole French territory. Both the CHIMERE model outputs and the Kriging process were validated. Our air pollutant exposure estimates considered the exposure at the residential address of the lung transplantation patients and did not account for space-time activity patterns. This limitation may not have major impact in our study, based mostly on housebound patients. Also, we excluded the lung function measurements performed in the first 6 months following the lung transplantation, as most patients spent part of this time in the hospital or rehabilitation centres. 
TABLE 3 Adjusted association of the tertiles of 12 months average of air pollutants exposure with levels of FEV $1 \%$ predicted and FVC \% predicted

\begin{tabular}{|c|c|c|c|c|c|c|}
\hline Tertiles of pollutants & \multicolumn{3}{|c|}{ FEV 1} & \multicolumn{3}{|c|}{ FVC } \\
\hline \multicolumn{7}{|l|}{ PM2.5 } \\
\hline First tertile & 0 & & 0.90 & 0 & & 0.04 \\
\hline Second tertile & $0.30 \pm 0.7$ & 0.67 & & $-0.55 \pm 0.59$ & 0.35 & \\
\hline Third tertile & $0.29 \pm 0.86$ & 0.73 & & $-1.77 \pm 0.73$ & 0.01 & \\
\hline \multicolumn{7}{|l|}{ PM10 } \\
\hline Third tertile & $0.35 \pm 1.04$ & 0.74 & & $-2.55 \pm 0.88$ & 0.004 & \\
\hline \multicolumn{7}{|l|}{$\mathrm{NO}_{2}$} \\
\hline First tertile & 0 & & 0.29 & 0 & & 0.35 \\
\hline Second tertile & $-2.13 \pm 1.36$ & 0.12 & & $-1.29 \pm 1.17$ & 0.27 & \\
\hline Third tertile & $-1.93 \pm 1.67$ & 0.25 & & $-2.08 \pm 1.44$ & 0.15 & \\
\hline \multicolumn{7}{|l|}{$\mathrm{O}_{3}$} \\
\hline
\end{tabular}

FEV1: forced expiratory volume in $1 \mathrm{~s}$; FVC: forced vital capacity; PMx: particulate matter with an aerodynamic cross section of $\mathrm{x} \mu \mathrm{m}$. Adjusted on recipient age (continuous), sex, smoking status of both donor and recipient, body mass index (continuous), donor age, type of lung transplant, underlying disease, sex mismatch, anti-human leukocyte antigen antibodies, transplant centre, on living area, treated Pseudomonas infection, cytomegalovirus treated disease, immunosuppression induction and acute rejection treated episodes. Number of subjects was 487 and number of measurements was 1751 .

The observed association between air pollutant exposures and FVC \% pred level may reflect a causal association, but might also be the result of residual spatial confounding. Indeed, some risk factors for lung function may vary with pollutants concentration across geographical area or regions and thus could induce spatial confounding [22, 24]. Noteworthy, although one cannot totally dismiss the risk for residual confounding in observational studies, the associations remained in sensitivity analyses aimed at reducing this bias. First, the association between a decreased FVC \% pred level and a higher 12-month average exposure of PM10, PM2.5 and $\mathrm{NO}_{2}$ remained significant or borderline significant when considering shorter exposure windows. Considering shorter windows of exposures adds temporal variability in exposure, therefore possibly limiting the potential for spatial residual confounding. Secondly, the analyses stratified on rural versus urban area showed that the increased exposure to $\mathrm{PM} 10$ and $\mathrm{NO}_{2}$ remained significantly associated with decreased FVC \% pred in the urban areas, probably a more homogeneous population as compared to the whole study population. However, when considering the 6-month average exposure after lung function tests, as expected under our working hypothesis, the magnitude of association decreased for $\mathrm{NO}_{2}$ and $\mathrm{PM}$ and became non-significant.

Our findings on $\mathrm{NO}_{2}$ and $\mathrm{PM}$ pollutants are in line with results from previous studies indicating that exposure to air pollutants might increase the risk for the development of CLAD and BOS (defined on the rate of change of FEV1 or FVC) and for mortality in post-transplant patients $[14,15]$. Road density within $200 \mathrm{~m}$ of a patient's home increased the risk for CLAD development in a Canadian cohort including 397 lung transplant patients [14]. Using the proximity of the home to major road as proxy of traffic-related air pollutant exposure, NAWROT et al. [15] showed in a cohort of 288 patients that patients living within $171 \mathrm{~m}$ of a major road developed twice more often BOS and died earlier than patients living farther away; however, the authors did not find any association between PM10 estimated at each patient's home using a model with a $4 \times 4 \mathrm{~km}$ resolution. The authors attributed this unexpected null finding to the limited spatial variation of the PM10, possibly in part explained by the limited spatial model resolution. The different outcomes and air pollution exposure assessment studied prevent any direct comparison among these studies.

Our results with ozone were either not significant or contradictory with our prior hypothesis. In our study, exposure measurement error was probably higher for ozone than for the other pollutants because the model used to estimate ozone exposure had a much lower spatial resolution $(4 \times 4 \mathrm{~km}$ versus $1 \times 1 \mathrm{~km})$. This, combined with the fact that ozone inversely correlates with $\mathrm{NO}_{2}$, made difficult the detection of any potential association. Moreover, outdoor ozone levels are poorly correlated with indoor levels as ozone quickly reacts with indoor air pollutants, limiting the relevance of a purely outdoor model, compared with the other pollutants considered. 
TABLE 4 Association of pollutant exposure with levels of FEV $1 \%$ predicted and FVC \% predicted in bi-pollutant models

\begin{tabular}{|c|c|c|c|c|}
\hline $\begin{array}{l}\text { Window of exposure/ } \\
\text { outcome }\end{array}$ & Beta \pm sE & p-value & Beta \pm sE & p-value \\
\hline 12 months & \multicolumn{2}{|c|}{$\mathrm{PM} 2.5\left(2 \mu \mathrm{g} \cdot \mathrm{m}^{-3}\right)$} & \multicolumn{2}{|c|}{$\mathrm{PM}_{10}\left(5 \mu \mathrm{g} \cdot \mathrm{m}^{-3}\right)$} \\
\hline FEV1 & $1.39 \pm 0.58$ & 0.02 & $-1.58 \pm 1.19$ & 0.19 \\
\hline \multirow[t]{2}{*}{ FVC } & $0.41 \pm 0.49$ & 0.40 & $-3.2 \pm 1.01$ & 0.002 \\
\hline & \multicolumn{2}{|c|}{$\mathrm{PM} 2.5\left(2 \mu \mathrm{g} \cdot \mathrm{m}^{-3}\right)$} & \multicolumn{2}{|c|}{$\mathrm{NO}_{2}\left(10 \mu \mathrm{g} \cdot \mathrm{m}^{-3}\right)$} \\
\hline FEV 1 & $1.47 \pm 0.45$ & 0.001 & $-3.81 \pm 1.41$ & 0.007 \\
\hline \multirow[t]{2}{*}{ FVC } & $-0.46 \pm 0.38$ & 0.24 & $-1.77 \pm 1.25$ & 0.16 \\
\hline & \multicolumn{2}{|c|}{ PM2.5 $\left(2 \mu \mathrm{g} \cdot \mathrm{m}^{-3}\right)$} & \multicolumn{2}{|c|}{$0_{3}\left(10 \mu \mathrm{g} \cdot \mathrm{m}^{-3}\right)$} \\
\hline FEV1 & $1.28 \pm 0.4$ & 0.001 & $5.04 \pm 1.19$ & $<0.0001$ \\
\hline \multirow[t]{2}{*}{ FVC } & $-0.61 \pm 0.33$ & 0.07 & $1.62 \pm 1.05$ & 0.13 \\
\hline & \multicolumn{2}{|c|}{$\mathrm{PM}_{10}\left(5 \mu \mathrm{g} \cdot \mathrm{m}^{-3}\right)$} & \multicolumn{2}{|c|}{$\mathrm{NO}_{2}\left(10 \mu \mathrm{g} \cdot \mathrm{m}^{-3}\right)$} \\
\hline $\mathrm{FEV}_{1}$ & $1.57 \pm 0.95$ & 0.1 & $-2.71 \pm 1.44$ & 0.06 \\
\hline \multirow[t]{2}{*}{ FVC } & $-2.4 \pm 0.81$ & 0.003 & $-0.44 \pm 1.27$ & 0.73 \\
\hline & \multicolumn{2}{|c|}{$\mathrm{PM}_{10}\left(5 \mu \mathrm{g} \cdot \mathrm{m}^{-3}\right)$} & \multicolumn{2}{|c|}{$0_{3}\left(10 \mu \mathrm{g} \cdot \mathrm{m}^{-3}\right)$} \\
\hline FEV 1 & $1.62 \pm 0.83$ & 0.05 & $4.72 \pm 1.21$ & $<0.0001$ \\
\hline \multirow[t]{2}{*}{ FVC } & $-2.34 \pm 0.7$ & 0.001 & $1.01 \pm 1.07$ & 0.35 \\
\hline & \multicolumn{2}{|c|}{$\mathrm{NO}_{2}\left(10 \mu \mathrm{g} \cdot \mathrm{m}^{-3}\right)$} & \multicolumn{2}{|c|}{$0_{3}\left(10 \mu \mathrm{g} \cdot \mathrm{m}^{-3}\right)$} \\
\hline FEV1 & $2.01 \pm 1.52$ & 0.19 & $5.16 \pm 1.47$ & 0.0005 \\
\hline FVC & $-1.96 \pm 1.32$ & 0.14 & $0.99 \pm 1.28$ & 0.44 \\
\hline 6 months & \multicolumn{2}{|c|}{ PM2.5 $\left(2 \mu \mathrm{g} \cdot \mathrm{m}^{-3}\right)$} & \multicolumn{2}{|c|}{$\mathrm{PM}_{10}\left(5 \mu \mathrm{g} \cdot \mathrm{m}^{-3}\right)$} \\
\hline \multirow{3}{*}{$\begin{array}{l}\text { FEV1 } \\
\text { FVC }\end{array}$} & $0.37 \pm 0.44$ & 0.4 & $-0.56 \pm 0.92$ & 0.55 \\
\hline & $-0.05 \pm 0.37$ & 0.89 & $-1.43 \pm 0.78$ & 0.07 \\
\hline & PM2.5 & & $\mathrm{NO}_{2}$ & \\
\hline $\mathrm{FEV} 1$ & $0.46 \pm 0.28$ & 0.10 & $-2.66 \pm 1.07$ & 0.01 \\
\hline \multirow[t]{2}{*}{ FVC } & $-0.37 \pm 0.23$ & 0.11 & $-2.08 \pm 0.93$ & 0.03 \\
\hline & \multicolumn{2}{|c|}{$\mathrm{PM} 2.5\left(2 \mu \mathrm{g} \cdot \mathrm{m}^{-3}\right)$} & \multicolumn{2}{|c|}{$o_{3}\left(10 \mu \mathrm{g} \cdot \mathrm{m}^{-3}\right)$} \\
\hline FEV1 & $0.17 \pm 0.25$ & 0.50 & $0.79 \pm 0.43$ & 0.07 \\
\hline \multirow[t]{2}{*}{ FVC } & $-0.59 \pm 0.21$ & 0.004 & $0.84 \pm 0.36$ & 0.02 \\
\hline & \multicolumn{2}{|c|}{$\mathrm{PM}_{10}\left(5 \mu \mathrm{g} \cdot \mathrm{m}^{-3}\right)$} & \multicolumn{2}{|c|}{$\mathrm{NO}_{2}\left(10 \mu \mathrm{g} \cdot \mathrm{m}^{-3}\right)$} \\
\hline $\mathrm{FEV} 1$ & $0.66 \pm 0.58$ & 0.26 & $-2.38 \pm 1.06$ & 0.02 \\
\hline \multirow[t]{2}{*}{ FVC } & $-1.08 \pm 0.49$ & 0.03 & $-1.84 \pm 0.92$ & 0.05 \\
\hline & \multicolumn{2}{|c|}{$\mathrm{PM}_{10}\left(5 \mu \mathrm{g} \cdot \mathrm{m}^{-3}\right)$} & $\mathrm{O}_{3} l$ & \\
\hline FEV 1 & $0.09 \pm 0.52$ & 0.86 & $0.78 \pm 0.43$ & 0.07 \\
\hline FVC & $-1.52 \pm 0.44$ & 0.001 & $0.87 \pm 0.36$ & 0.02 \\
\hline & $\mathrm{NO}_{2}$ & & $\mathrm{O}_{3} l$ & \\
\hline $\mathrm{FEV} 1$ & $-1.25 \pm 1.18$ & 0.29 & $0.45 \pm 0.54$ & 0.41 \\
\hline FVC & $-2.43 \pm 1.02$ & 0.02 & $0.24 \pm 0.45$ & 0.59 \\
\hline
\end{tabular}

FEV1: forced expiratory volume in $1 \mathrm{~s}$; FVC: forced vital capacity; Model adjusted on recipient age (continuous), sex, smoking status of both donor and recipient, body mass index (continuous), donor age, type of lung transplant, underlying disease, sex mismatch, anti-human leukocyte antigen antibodies, transplant centercentre, on living area, treated Pseudomonas infection, cytomegalovirus treated disease, immunosuppression induction and acute rejection treated episodes, for the 6-month exposure on temperature and humidity, estimated on 487 patients (1751 measurements).

Air pollution might influence pulmonary function in LTRs through inflammatory and immune mechanisms. Experimental studies indicate that chronic exposure to particulate air pollutants has an impact on the pulmonary T cell activation [25]. Short-term exposure to diesel exhaust, one of the major contributors to inhaled PM pollution, induces an acute inflammatory response in the airways of healthy individuals [26]. In 
LTRs, higher short-term exposure to PM increased the risk for lymphocytic bronchiolitis, which was associated with further development of BOS, and increased airway neutrophilic inflammation [27]. Our findings expand results from a recent observational study indicating that the deleterious effects of air pollution in LTRs might be modified by macrolides [16]. The anti-inflammatory effects of the macrolides could explain this observation. Indeed, macrolide antibiotics either used as curative treatment in BOS patients or as preventive treatment improved health outcomes in LTRs, in particular through its anti-inflammatory and immunomodulatory properties [28-30]. The molecular mechanisms of anti-inflammatory effects of macrolides include the inhibition of pro-inflammatory transcription factors such as nuclear factor- $\kappa \mathrm{B}$ [31]. Although there is a biological plausibility supporting that macrolides might reduce the deleterious effects of air pollution in lung transplantation patients, we cannot dismiss possible selection bias in our findings, or differences in sensitivity to air pollutants due to factors other than macrolides, since the groups with and without macrolides differed in many respects.

In the present study, exposure to $\mathrm{NO}_{2}$ and $\mathrm{PM} 10$ was associated with lower FVC but not with FEV1. The unexpected positive association between PM2.5 exposure and FEV1 should be disregarded as this association totally disappeared when considering the tertiles of PM2.5 exposure. In patients not using macrolides, our results indicate that PM10 might have a deleterious effect on both lung volumes and flows. Further studies are needed to investigate the respective effects of long-term exposure to air pollution on level and changes in lung volumes and flows.

In conclusion, our study adds to the growing body of literature indicating that chronic exposure to air pollution has deleterious effect on respiratory health and specifically in LTRs. The magnitude of effects observed is clinically relevant and raises the issue of considering air pollutant exposure in LTRs to protect patients from environmental hazards besides home fungal risk, compliance issues or smoking relapse.

\section{Acknowledgements}

Cohort Of Lung Transplantation-COLT (associating surgeons; anaesthetists-intensivists; physicians, research staff): J. Jougon, J-F. Velly, H. Rozé, E. Blanchard, C. Dromer (Bordeaux, France); M. Antoine, M. Cappello, M. Ruiz, Y. Sokolow, F. Vanden Eynden, G. Van Nooten; L. Barvais, J. Berré, S. Brimioulle, D. De Backer, J. Créteur, E. Engelman, I. Huybrechts, B. Ickx, T.J.C. Preiser, T. Tuna, L. Van Obberghe, N. Vancutsem, J-L. Vincent; P. De Vuyst, I. Etienne, F. Féry, F. Jacobs, C. Knoop, J.L. Vachiéry, P. Van den Borne, I. Wellemans; G. Amand, L. Collignon, M. Giroux (Brussels, Belgium); E. Arnaud-Crozat, V. Bach, O. Chavanon, A. de Lambert, J-P. Fleury, S. Guigard, R. Hacini, K. Hireche, A. Pirvu, P. Porcu; P. Albaladejo, C. Allègre, A. Bataillard, D. Bedague, E. Briot, M. Casez-Brasseur, D. Colas, G. Dessertaine, M. Durand, G. Francony, A. Hebrard, M.R. Marino, B. Oummahan, D. Protar, D. Rehm, S. Robin, M. Rossi-Blancher; C. Augier, P. Bedouch, A. Boignard, H. Bouvaist, E. Brambilla, A. Briault, B. Camara, J. Claustre, S. Chanoine, M. Dubuc, S. Quétant, J. Maurizi, P. Pavèse, C. Pison, C. Saint-Raymond, N. Wion, C. Chérion (Grenoble, France); R. Grima, O. Jegaden, J.-M. Maury, F. Tronc; C. Flamens, S. Paulus; J-F. Mornex, F. Philit, A. Senechal, J-C. Glérant, S. Turquier; D. Gamondes; L. Chalabresse, F. Thivolet-Bejui; C Barnel, C. Dubois, A. Tiberghien (Lyon, France); F. Le Pimpec-Barthes, A. Bel, P. Mordant, P. Achouh; V. Boussaud; R. Guillemain, D. Méléard, M.O. Bricourt, B. Cholley ; V. Pezella (Hôpital Européen Georges Pompidou, Paris, France); G. Brioude, X.B. D’Journo, C. Doddoli. P. Thomas, D. Trousse ; S. Dizier, M. Leone, L. Papazian; F. Bregeon, B. Coltey, N. Dufeu, H. Dutau, S. Garcia, J.Y. Gaubert, C. Gomez, S. Laroumagne, G. Mouton, A. Nieves, C. Picard, M. Reynaud-Gaubert, J.M. Rolain, E. Sampol, V. Secq (Marseille, France), O. Baron, P. Lacoste, C. Perigaud, J. C. Roussel; I. Danner, A Haloun A. Magnan, A Tissot; T. Lepoivre, M. Treilhaud; K. Botturi-Cavaillès, S. Brouard, R. Danger, J. Loy, M. Morisset, M. Pain, S. Pares, D. Reboulleau, P-J. Royer (Nantes, France); P. Dartevelle, D. Fabre, E. Fadel, O. Mercier, S. Mussot; F. Stephan, P. Viard; J. Cerrina, P. Dorfmuller, S. Feuillet M. Ghigna, Ph. Hervén F. Le Roy Ladurie, J. Le Pavec, V. Thomas de Montpreville; L. Lamrani (Hôpital Marie Lannelongue, Le Plessis Robinson, France); Y. Castier, P. Mordant, P. Cerceau, P. Augustin, S. Jean-Baptiste, S. Boudinet, P. Montravers ; O. Brugière, G. Dauriat, G. Jébrak, H. Mal, A. Marceau, A.-C. Métivier, G. Thabut, E. Lhuillier, C. Dupin, V. Bunel (Hôpital Bichat, Paris, France); P. Falcoz, G. Massard, N. Santelmo; G. Ajob, O. Collange O. Helms, J. Hentz, A. Roche; B. Bakouboula, T. Degot, A. Dory, S. Hirschi, S. Ohlmann-Caillard, L. Kessler, R. Kessler, A. Schuller; K. Bennedif, S. Vargas (Strasbourg, France); P. Bonnette, A. Chapelier, P. Puyo, E. Sage; J. Bresson, V. Caille, C. Cerf, J. Devaquet, V. Dumans-Nizard, ML. Felten, M. Fischler, AG. Si Larbi, M. Leguen, L. Ley, N. Liu, G. Trebbia; S. De Miranda, B. Douvry, F. Gonin, D. Grenet, A.M. Hamid, H. Neveu, F. Parquin, C. Picard, A. Roux, M. Stern; F. Bouillioud, P. Cahen, M. Colombat, C. Dautricourt, M. Delahousse, B. D'Urso, J. Gravisse, A. Guth, S. Hillaire, P. Honderlick, M. Lequintrec, E. Longchampt, F. Mellot, A. Scherrer, L. Temagoult, L. Tricot; M. Vasse, C. Veyrie, L. Zemoura (Suresnes, France); J. Berjaud, L. Brouchet, M. Dahan; F. Le Balle, O. Mathe; H. Benahoua, A. Didier, A.L. Goin, M. Murris; L. Crognier, O. Fourcade (Toulouse, France).

Swiss Transplant Cohort Study-STCS: T. Krueger, H.B. Ris, M. Gonzalez; J-D. Aubert, L.P. Nicod, B.J. Marsland, T. C. Berutto, T. Rochat, P. Soccal, P. Jolliet, A. Koutsokera, C. Marcucci, O. Manuel; E. Bernasconi, M. Chollet, F. Gronchi C Courbon; Zurich S. Hillinger, I. Inci, P. Kestenholz, W. Weder; R. Schuepbach, M. Zalunardo; C. Benden, U. Buergi, L.C. Huber; B. Isenring, M.M. Schuurmans; A. Gaspert, D. Holzmann, N. Müller, C. Schmid, B. Vrugt, T. Rechsteiner (Geneva and Lausanne, Switzerland).

A. Fritz, D. Maier (SME and Platforms Biomax, Planneg, Germany); K. Deplanche, D. Koubi (Finovatis, Lyon, France); F. Ernst, T. Paprotka, M. Schmitt, B. Wahl (GATC, Konstanz, Germany); J-P. Boissel, G. Olivera-Botello (NovaDiscovery, Lyon, France); C. Trocmé, B. Toussaint, S. Bourgoin-Voillard, M. Séve (Prométhée Proteomics Platform, Grenoble, France); M. Benmerad, V. Siroux, R. Slama (IAB UGA-Inserm U1209, Grenoble, France); C. Auffray, D. Charron, D. Lefaudeux, J. Pellet (European Institute for Systems Biology \& Medicine, Lyon, France). 
We thank X. Morelli (IAB UGA-Inserm U1209, Grenoble, France) for preparing the maps showing the 12-month air pollutants concentration. We thank C. Pennequin from INERIS (Verneuil-en-Halatte, France) for her contribution to the development of air pollution exposure models. The authors are indebted to all the individuals who participated to the COLT cohort, without whom, this study would not have been possible.

\section{References}

1 Yusen RD, Edwards LB, Kucheryavaya AY, et al. The registry of the International Society for Heart and Lung Transplantation: thirty-first adult lung and heart-lung transplant report, 2014; focus theme: retransplantation. J Heart Lung Transplant 2014; 33: 1009-1024.

2 Weigt SS, DerHovanessian A, Wallace WD, et al. Bronchiolitis obliterans syndrome: the Achilles' heel of lung transplantation. Semin Respir Crit Care Med 2013; 34: 336-351.

3 Verleden GM, Vos R, Vanaudenaerde B, et al. Current views on chronic rejection after lung transplantation. Transpl Int 2015; 28: 1131-1139.

4 Schikowski T, Adam M, Marcon A, et al. Association of ambient air pollution with the prevalence and incidence of COPD. Eur Respir J 2014; 44: 614-626.

5 Young MT, Sandler DP, DeRoo LA, et al. Ambient air pollution exposure and incident adult asthma in a nationwide cohort of US women. Am J Respir Crit Care Med 2014; 190: 914-921.

6 Adam M, Schikowski T, Carsin AE, et al. Adult lung function and long-term air pollution exposure. ESCAPE: a multicentre cohort study and meta-analysis. Eur Respir J 2014.

7 Lepeule J, Litonjua AA, Coull B, et al. Long-term effects of traffic particles on lung function decline in the elderly. Am J Respir Crit Care Med 2014; 190: 542-548.

8 Jacquemin B, Siroux V, Sanchez M, et al. Ambient air pollution and adult asthma incidence in six European cohorts (ESCAPE). Environ Health Perspect 2015; 123: 613-621.

9 Rice MB, Ljungman PL, Wilker EH, et al. Long-term exposure to traffic emissions and fine particulate matter and lung function decline in the Framingham heart study. Am J Respir Crit Care Med 2015; 191: 656-664.

10 Gehring U, Gruzieva O, Agius RM, et al. Air pollution exposure and lung function in children: the ESCAPE project. Environ Health Perspect 2013; 121: 1357-1364.

11 Gauderman WJ, Vora H, McConnell R, et al. Effect of exposure to traffic on lung development from 10 to 18 years of age: a cohort study. Lancet 2007; 369: 571-577.

12 Gauderman WJ, Urman R, Avol E, et al. Association of improved air quality with lung development in children. N Engl J Med 2015; 372: 905-913.

13 Downs SH, Schindler C, Liu LJ, et al. Reduced exposure to PM10 and attenuated age-related decline in lung function. N Engl J Med 2007; 357: 2338-2347.

14 Bhinder S, Chen $\mathrm{H}$, Sato $\mathrm{M}$, et al. Air pollution and the development of posttransplant chronic lung allograft dysfunction. Am J Transplant 2014; 14: 2749-2757.

15 Nawrot TS, Vos R, Jacobs L, et al. The impact of traffic air pollution on bronchiolitis obliterans syndrome and mortality after lung transplantation. Thorax 2011; 66: 748-754.

16 Ruttens D, Verleden SE, Bijnens EM, et al. An association of particulate air pollution and traffic exposure with mortality after lung transplantation in Europe. Eur Respir J 2017; 49: 1600484.

17 Pison C, Magnan A, Botturi K, et al. Prediction of chronic lung allograft dysfunction: a systems medicine challenge. Eur Respir J 2014; 43: 689-693.

18 Quanjer PH, Stanojevic S, Cole TJ, et al. Multi-ethnic reference values for spirometry for the 3-95-yr age range: the global lung function 2012 equations. Eur Respir J 2012; 40: 1324-1343.

19 Alonso R, Vivanco MG, Gonzalez-Fernandez I, et al. Modelling the influence of peri-urban trees in the air quality of Madrid region (Spain). Environ Pollut 2011; 159: 2138-2147.

20 Valari M, Menut L, Chatignoux E. Using a chemistry transport model to account for the spatial variability of exposure concentrations in epidemiologic air pollution studies. J Air Waste Manag Assoc 2011; 61: 164-179.

21 Jacquemin B, Lepeule J, Boudier A, et al. Impact of geocoding methods on associations between long-term exposure to urban air pollution and lung function. Environ Health Perspect 2013; 121: 1054-1060.

22 Pedersen M, Siroux V, Pin I, et al. Does consideration of larger study areas yield more accurate estimates of air pollution health effects? An illustration of the bias-variance trade-off in air pollution epidemiology. Environ Int 2013; 60C: 23-30.

23 Urschel S. Apples, oranges, and statistical magic: Limitations of registry studies and need for collaborative studies. J Heart Lung Transplant 2015; 34: 1136-1138.

24 Flanders WD, Klein M, Darrow LA, et al. A method to detect residual confounding in spatial and other observational studies. Epidemiology 2011; 22: 823-826.

25 Deiuliis JA, Kampfrath T, Zhong J, et al. Pulmonary $\mathrm{T}$ cell activation in response to chronic particulate air pollution. Am J Physiol Lung Cell Mol Physiol 2012; 302: L399-L409.

26 Salvi SS, Nordenhall C, Blomberg A, et al. Acute exposure to diesel exhaust increases IL-8 and GRO-alpha production in healthy human airways. Am J Respir Crit Care Med 2000; 161: 550-557.

27 Verleden SE, Scheers H, Nawrot TS, et al. Lymphocytic bronchiolitis after lung transplantation is associated with daily changes in air pollution. Am J Transplant 2012; 12: 1831-1838.

28 Corris PA, Ryan VA, Small T, et al. A randomised controlled trial of azithromycin therapy in bronchiolitis obliterans syndrome (BOS) post lung transplantation. Thorax 2015; 70: 442-450.

29 Vos R, Verleden SE, Ruttens D, et al. Azithromycin and the treatment of lymphocytic airway inflammation after lung transplantation. Am J Transplant 2014; 14: 2736-2748.

30 Ruttens D, Verleden SE, Vandermeulen E, et al. Prophylactic azithromycin therapy after lung transplantation: post hoc analysis of a randomized controlled trial. Am J Transplant 2016; 16: 254-261.

31 Li M, Zhong X, He Z, et al. Effect of erythromycin on cigarette-induced histone deacetylase protein expression and nuclear factor-kappaB activity in human macrophages in vitro. Int Immunopharmacol 2012; 12: 643-650. 